\title{
THE ALTERNATIVE CAPITAL OF THE USSR: ESTIMATES OF THE AMERICAN PRESS AND SPECIAL SERVICES
}

(C) 2017

\author{
Buranok Sergey Olegovich, doctor of historical sciences, \\ associate professor of World History, Law and Methods of Teaching Department \\ Levin Yaroslav Alexandrovich, candidate of historical sciences, \\ junior researcher of World History, Law and Methods of Teaching Department \\ Sokolova Anna Vyacheslavovna, student of History Faculty \\ Samara State University of Social Sciences and Education (Samara, Russian Federation)
}

Abstract. The following paper for the first time in Samara regional studies deals with the study of significance of Kuibyshev in the public opinion of the USSR allies. Having become a reserved capital, Kuibyshev ceased to be just one of the regional centers in the Soviet Union, it turned into a city known and significant all over the world. This paper uses many unique US documents on Kuibyshev during the war. On their basis the authors analyze formation and perception of the image of the reserved capital in American society. To study the history of Kuibyshev as a second capital at such an angle is important for imagology, study of local lore and comparative studies. The conducted research showed how the image of Kuibyshev was made in the conditions of the Second World War, how its perception changed. The paper also uses the data of the US special services that makes it possible to understand what place Kuibyshev was given at that time by representatives of the intelligence community of America. The study of Kuibyshev image in the assessments of the American special services opens a possibility for researchers to get acquainted with their work from a new perspective. The paper draws conclusions about the influence of certain journalists on the formation of Kuibyshev image. The conclusions drawn in this paper, as well as the introduction of new documents into circulation, will allow us to deepen and expand this topic in the future.

Keywords: Second World War; Great Patriotic War; Kuibyshev; Samara; Samara Region; Imagology; alternative capital; Federal Bureau of Investigation; Associated Press; USA; Henri Cassidy; Eddie Gilmour; Henry Shapiro; Walter Kerr; Archibald Steele; special services; Pearl Harbor; Pacific War.

УДК 94(470.41) "1941/1945"

\section{СОЦИАЛЬНАЯ АДАПТАЦИЯ И ТРУДОУСТРОЙСТВО ИНВАЛИДОВ В ГОДЫ ВЕЛИКОЙ ОТЕЧЕСТВЕННОЙ ВОЙНЫ (НА МАТЕРИАЛАХ ТАТАРСКОЙ АССР)}

(C) 2017

\author{
Кабирова Айслу Шарипзяновна, доктор исторических наук, \\ ведущий научный сотрудник отдела новейшей истории \\ Институт истории им. Ш. Марджани Академии наук Республики Татарстан \\ (2. Казань, Российская Федерация)
}

Аннотация. В статье рассматриваются проблемы социальной адаптации инвалидов Великой Отечественной войны в Татарской АССР после возвращения их к мирной жизни. На основе документальных материалов, извлеченных из фондов федеральных и татарстанских архивов, характеризуются формы государственной поддержки искалеченных войной людей, решение вопросов их производственного обучения и трудоустройства, назначения пенсий, открытия домов-интернатов, организации медико-санитарного обслуживания и т.д. Отмечается, что для большинства инвалидов такая адресная поддержка являлась зачастую определяющей в обеспечении их жизнедеятельности. Трудоустройство инвалидов Отечественной войны позволяло решить двуединую задачу - в условиях острого дефицита рабочих рук создавался новый кадровый резерв для экономики и одновременно обеспечивалась социальная защита вернувшихся после лечения в госпиталях фронтовиков. Многие инвалиды Великой Отечественной войны хорошо зарекомендовали себя на производстве. Они становились передовиками, выдвигались на руководящие должности. Но были и те, кто вел аморальный образ жизни, занимался попрошайничеством. Властные органы, призванные решать вопросы социальной реабилитации инвалидов, не всегда справлялись с возложенными на них задачами. Свидетельством этого являются зафиксированные в источниках факты бездушно-бюрократического отношения отдельных чиновников к нуждам и запросам инвалидов, случаи присваивания денежных средств и разбазаривания государственных фондов.

Ключевые слова: Великая Отечественная война; Татарская АССР; фронтовики; инвалиды войны; адресная поддержка; государственная помощь; социальная адаптация; социальная защита; реабилитация; пенсии; пособия; трудовая политика; производственное обучение; трудоустройство; интернаты для инвалидов.

История не знала примеров столь массового героизма, какой проявили советские воины в годы Великой Отечественной войны. Ратные подвиги фронтовиков до сих пор остаются предметом восхищения и изучения как отечественных историков, так и зару- бежных специалистов. Но стойкость, мужество и доблесть бойцов во время ожесточенных столкновений с противником нередко сопровождались тяжелыми ранениями и травмами. Немало увечий получали и мирные жители от боевых действий в приф- 
ронтовой полосе, во время налетов авиации и т.д. Согласно данным советской и зарубежной печати, инвалидность при ранениях в годы Второй мировой войны по сравнению с Первой мировой возросла в 2,5 раза $[1$, с. 20]. По подсчетам М.С. Зинич, в РСФСР, по состоянию на 1 августа 1943 г., в органах социального обеспечения числилось 590,3 тыс. инвалидов Отечественной войны, в начале 1945 г. 1 млн. 139,6 тыс. [1, с. 21].

Проблемы реабилитации и социальной адаптации демобилизованных инвалидов, взаимоотношений их с властными органами поднимали в своих трудах многие известные специалисты: М.С. Зинич [1], А.М. Синицын [2], Н.П. Палецких [3], Е.В. Панарина [4], А.В. Шалак [5] и др. Однако отдельные аспекты темы все еще остаются недостаточно исследованными. В данной статье ставится цель - на основе архивных источников и материалов рассмотреть, насколько эффективно решались вопросы социальной защиты и трудоустройства инвалидов-фронтовиков в годы Великой Отечественной войны в одном из тыловых регионов страны - Татарской АССР.

По официальным сведениям, на 1 декабря 1943 г. в ТАССР проживало 24267 инвалидов войны, из них: 387 человек - I-й группы, 9745 - II-й группы, 14135 III-й группы $[6$, л. 1]. К концу войны число инвалидов существенно увеличилось. По данным на 1 мая 1945 г., их в республике было уже 40043 чел. Распределение по группам выглядело следующим образом: 574 чел. - инвалиды I-й группы, 15589 - II-й, 23880 - III-й группы [7, л. 2]. І-ю группу инвалидности составляли лица, полностью утратившие трудоспособность и нуждавшиеся в постороннем уходе, IIю группу - утратившие способность трудиться по какой бы то ни было специальности, III-ю группу неспособные к систематическому труду по своей профессии, но которые вполне могли использоваться на более легких работах.

Государство выплачивало демобилизованным инвалидам пенсии, правда, уровень их был низким. Средний размер пенсии офицера составлял 360 руб., рядового - меньше. Повышенную пенсию получали инвалиды, награжденные орденом Славы трех степеней [3, с. 153]. Однако, учитывая дороговизну продуктов и промтоваров в военные годы, рассчитывать на выживание только за счет этих денежных выплат не приходилось. Достаточно сказать, что цены на рынках крупных городов в годы войны повысились в 13 раз и превышали уровень цен на продукты, продававшиеся по карточкам, в 20 с лишним раз [8, c. 285]. В источниках фиксировались сведения о нищенстве и попрошайничестве инвалидов, случаях собирания милостыни и т.д. [9, л. 83-84].

Для преодоления такого положения было принято решение обратить особое внимание на трудоустройство инвалидов. Государственные органы тем самым одновременно решали двуединую задачу: создавали новый кадровый резерв для экономики и обеспечивали социальную защиту искалеченных войной людей. 6 мая 1942 г. СНК СССР опубликовал Постановление «О трудовом устройстве инвалидов Отечественной войны», согласно которому при исполкомах создавались специальные комиссии с целью организации массового обучения инвалидов новым специальностям. 20 января 1943 г. вышло новое По- становление правительства СССР «О мерах по трудовому устройству инвалидов Отечественной войны», обязывавшее республиканские Наркомсобесы в трехмесячный срок устроить на производство всех инвалидов III-й группы [10, с. 80-81].

В ТАССР наиболее распространенными формами обучения инвалидов являлись госпитальное и индивидуально-ведомственное. Судя по архивным данным, обучение новым профессиям было организовано более чем в 10 госпиталях республики, базовыми при этом стали два госпиталя г. Казани: № 4642 и № 1311. По состоянию на 1 декабря 1943 г., новые профессии здесь получили 2167 чел., в том числе было подготовлено: счетоводов - 558 чел., бухгалтеров - 280 чел., сапожников - 361 чел., портных - 148 чел., механиков - 15 чел., пчеловодов - 144 чел., животноводов - 285 чел. Встречались и более редкие специальности: стенографисты, морзисты, часовые мастера, цветочники, чертежники и т.д. [6, л. 2-2 об.].

Кроме того, в городах и районах республики организовывались межрайонные курсы, специализированные профшколы при интернатах. Большое количество будущих специалистов проходило через индивидуально-групповое обучение на предприятиях, когда желающие получить новую профессию прикреплялись к лучшим производственникам.

Всего в 1943 г. в республике работали и обучались 19672 инвалида Отечественной войны из имевшихся 24267 чел., что составляло $81,1 \%$ от общего их числа. Большинство инвалидов были заняты в сельском хозяйстве - 12486 чел., в промышленности - 1611 чел., в учреждениях - 4588 чел., остальные - в иных организациях [6, л. 1].

В условиях острого дефицита кадров приветствовалось выдвижение хорошо зарекомендовавших себя инвалидов на руководящие должности. Особенно много их было в аграрном производстве. На 1 октября 1943 г. в республике председателями колхозов работали 653 инвалида войны, председателями сельсоветов - 408 чел., бригадирами в колхозах - 1315 чел., счетоводами - 536 чел., директорами совхозов и МТC - 60 чел., агротехниками и агрономами - 61 чел. [6, л. 1 об.].

Многие инвалиды Великой Отечественной войны достойно справлялись со своей работой, становились передовиками производства. Их имена зафиксированы в отчетах о деятельности Наркомата соцобеспечения ТАССР. В частности, как особо положительная охарактеризована работа председателя колхоза «Акчишма» Ютазинского района инвалида Фахреева; слесаря по ремонту сельскохозяйственных машин свиноводческого комплекса «Нырты» Бусыгина. Значительное число инвалидов были заняты на промышленных предприятиях. На руководящих должностях только по г. Казани работали 375 чел. Например, инвалид Парвин являлся коммерческим директором 3-й швейной фабрики; Атеев - коммерческим директором фабрики «Светоч»; Семенкин работал начальником отдела завода «Серп и молот)» [7, л. 2, 6 об.].

Однако не везде дело обстояло столь благополучно. В некоторых районах работа по организации трудоустройства инвалидов не была развернута в необходимых объемах. Так, в Чистопольском районе рес- 
публики в 1943 г. трудоустроено было лишь $38 \%$ инвалидов войны, Высокогорском - 39\%, Тетюшском $42 \%$ [11, л. 23].

Недостаточный контроль со стороны органов социального обеспечения отражался и на качественной стороне трудоустройства инвалидов. Многие из них, даже при возможности, мало использовались по их прежней или родственной квалификации, что подтверждается следующими цифрами: в декабре 1944 г. из 1838 работающих инвалидов Отечественной войны III-й группы по г. Казани по своей основной или родственной специальности трудились только 164 чел. (9\%). Нередко за высокими процентами занятости стоял малоквалифицированный и низкооплачиваемый труд вахтеров, сторожей, швейцаров. На таких «тупиковых», как их называли, должностях из общего количества в 2078 чел. было занято 356 инвалидов [6, л. 2].

Нелицеприятную правду о действительном состоянии дел в этой сфере отразила в своем выступлении на заседании правительства республики Нарком социального обеспечения Татарской АССР М.Ф. Гайнутдинова. На одном из заседаний она подчеркивала: «Вопросами производственного переобучения и приспособления рабочего места для инвалидов отделы социального обеспечения занимаются неудовлетворительно, слабая связь с профсоюзными организациями промышленных предприятий, с отделами организации труда фабрик и заводов, в результате чего количество работающих инвалидов Отечественной войны на ведущих предприятиях весьма незначительно» $[6$, л. 2].

В дальнейшем, благодаря усилению внимания высоких инстанций к вопросам профессиональной переквалификации и трудоустройства инвалидов, ситуация несколько улучшилась. К маю 1945 г. из 40043 инвалидов, проживавших в Татарстане, трудоустроено было 32424 чел., обучалось - 1066 чел., т.е. всего работало и обучалось 33490 чел. Соответственно средние показатели по трудоустройству инвалидов за 1943-1945 гг. по республике выросли с $81,1 \%$ до $83,6 \%$ [7, л. 2].

Для тех, кто нашел себя в новой профессии и устроился на работу, социальная адаптация проходила быстро и успешно. Они благодарили административные органы, выражали свою признательность врачам и преподавателям. Так, бывший раненый госпиталя № 4642 Будко, направленный после выздоровления и получения новой специальности техником-животноводом в одну из освобожденных от фашистов областей, писал профессору А.А. Студенцову: «Жму правую руку и еще раз благодарю за Вашу заботу о нас, инвалидах Отечественной войны, за Вашу учебу, это дает нам возможность трудиться по нашей трудоспособности» [6, л. 2 об.].

Вместе с тем весьма значительный процент составляли инвалиды, которые бросали учебу, или, закончив обучение, не трудоустраивались, или, придя на предприятие, попадали в число нарушителей трудовой дисциплины. Например, из 89 официально закрепленных на заводе № 237 инвалидов Отечественной войны реально на производство выходили только 58 человек, остальные 31 чел. не работали, «устраивали пьянки» [12, л. 74 об.]. В архивных документах приводятся сведения о том, что многие «инвалиды III-й группы отказываются от работы без уважительных причин, занимаются спекуляцией, хулиганством». Некоторые из них за необоснованный отказ от работы лишались пенсии. Имелись также прецеденты привлечения инвалидов к судебной ответственности за действия криминального характера [7, л. 2 об.].

Важную роль в социальной реабилитации инвалидов играли лечебно-оздоровительные мероприятия и обустройство жизни и быта тех из них, кто не имел возможности работать и не имел дома. Для них в 1942 г. были организованы интернаты и дома инвалидов. К лету 1944 г. в Российской Федерации функционировало 323 дома инвалидов и 136 интернатов [1, c. 29].

В Татарской АССР для инвалидов Отечественной войны было открыто 3 интерната: два - общего типа в гг. Казани и Мензелинске (на 600 койко-мест), один - больничного типа для больных туберкулезом в г. Мензелинске (на 200 койко-мест) и 8 домов для инвалидов (на 774 койко-мест) [13, л. 39]. В качестве хорошо работавших в источниках назывались Чистопольские дома инвалидов № 1 и № 2. Здесь было организовано качественное питание, проведен ремонт зданий, налажено подсобное хозяйство [14, л. 18 об.]. Но к деятельности других домов инвалидов и интернатов имелись существенные претензии. Так, в Тетюшском индоме № 1 произведенной финансовой ревизией было установлено, что вместо утвержденных по смете на питание 3 руб. 50 коп. на каждого человека фактически расходовалось только 2 руб. 38 коп., т.е. недорасход составлял 1 руб. 12 коп. в день на каждого проживающего. В Лаишевском индоме часть продуктов выдавалась на руки в сухом виде, что было совершенно недопустимым, т.к. все продукты должны были закладываться в общий котел. В ряде случаев, в результате отсутствия контроля со стороны дирекции за приготовлением и раздачей пищи, имело место разбазаривание продуктов [7, л. 16 об.-17].

Неблагополучным признавалось и санитарно-гигиеническое обслуживание проживавших в домах инвалидов. Проверками было установлено, что посещение бани было нерегулярным, постельные принадлежности и нательное белье инвалидов находились в антисанитарном состоянии. Жилые помещения имели неуютный вид, в палатах отмечался беспорядок. Отдельные заведения влачили жалкое существование. Вот как на страницах официальных документов описывается состояние Елабужского инвалидного городка в декабре 1944 г.: «Жилищные помещения, а также все надворные постройки инвалидного городка запущены до самого отвратительного и в дальнейшем нетерпимого состояния, а именно: все печи жилищных помещений требуют перекладки... В большинстве палат стекла разбиты, рамы сгнившие, сломаны... Крыши отдельных корпусов худые, и при дождливой погоде потолки палат протекают, штукатурка потолков отвалилась...» [14, л. 19]. 
Плохо была поставлена в домах инвалидов политико-воспитательная и культурно-массовая работа, отмечались случаи, когда проживавшие в них «занимались воровством, азартными картежными играми, устраивали дебоши и поножовщину...» [11, л. 25].

Неотъемлемой частью реабилитационных мероприятий для инвалидов Отечественной войны в государстве должна была стать организация специализированного лечения и, прежде всего, такая составная ее часть, как протезирование. В Татарской АССР имелось значительное количество дееспособных инвалидов, для которых протезирование могло бы стать решением проблемы трудоустройства, но малые объемы работы протезных мастерских не позволяли полностью охватить всех желающих. Здесь в военный период работала только одна протезная мастерская, и она с возросшими объемами по изготовлению протезов не справлялась. Несмотря на то, что этот вопрос находился на контроле у обкома партии и правительства республики, положение мало менялось. Целевые средства, ассигнованные правительством, осваивались медленно. Так, из 340 тыс. руб., выделенных в 1942 г. для протезной мастерской, израсходовано оказалось лишь 195 тыс. руб., в связи с чем производственный план 1942 г. был выполнен всего на 47,1\%. Это в свою очередь приводило к тому, что из-за отсутствия протезов многие ранбольные, подлежащие выписке, не могли покинуть госпитали в течение 4-6 месяцев. Достаточно сказать, что только в одном казанском госпитале № 1311 в 1943 г. вместо 260 койко-дней на 26 ранбольных было использовано 2417 койко-дней [11, л. 25-26].

Заявки, поступавшие в отделы Наркомата социального обеспечения республики на протезы, лежали без движения до 13 дней, а в самой протезной мастерской изготовление их затягивалось на 3-5 месяцев. Например, по Челнинскому району ТАССР заказы на изготовление протезов для инвалидов Отечественной войны были приняты 1 августа 1942 г., а Наркомсобесом сданы в мастерскую только 10 сентября 1942 г.; по Мензелинскому району - заказы приняты 24 сентября 1942 г., а протезы изготовлены в январе 1943 г. [11, л. 25].

Большое разочарование у инвалидов вызывала также неудовлетворительная практика исполнения законов советского государства по части назначения им пенсий и полагавшихся льгот. Согласно нормативам, за работающими на предприятиях и в учреждениях сохранялась выплата пенсий независимо от размера их заработной платы, а за работающими в колхозах - независимо от размера их дохода. Инвалиды Отечественной войны освобождались от платы за обучение в техникумах и вузах. Кроме того, бывшим воинам полагался целый ряд льгот по налогообложению.

Пенсии инвалидам назначались комиссиями при рай(гор)собесах. Но источники фиксируют большие недостатки и нарушения в этой области $[15$, л. 7]. Так, в справке о состоянии работы Наркомата социального обеспечения ТАССР за 1943 г. отмечается: «Многие отделы социального обеспечения грубо нарушают установленный порядок по рассмотрению дел о назначении и выплате пенсий инвалидам Отечественной войны. В г. Зеленодольске из 223 дел о назначении пенсий 105 рассмотрено с нарушением срока на 15-20 дней, причем в ряде случаев назначение пенсии разрешено лично заведующим горсобесом Криневским, а не комиссией по назначению пенсий» [11, л. 26; 16, л. 34].

В ходе проверок работы отделов соцобеспечения выявлялись случаи прямых злоупотреблений служебным положением и хищений денежных средств, предназначенных для выплаты пенсий инвалидам войны. Специальная комиссия Наркомата Госконтроля РСФСР, работавшая в ТАССР в декабре 1942 марте 1943 гг., раскрыла механизмы совершения таких финансовых махинаций. Было установлено, к примеру, что инспектор Дзержинского райсобеса Л.Н. Горшунова, которой было поручено составление ведомостей и выплата пенсий в госпиталях, вписывала в пенсионные ведомости вымышленных лиц, расписывалась за них, а деньги присваивала. Всего по 7 ведомостям ею было присвоено 4410 руб. [17, л. 17-17 об.]. На 1 января 1943 г. в целом по республике не было выплачено в установленный срок более 2 млн. руб. пособий семьям военнослужащих и пенсий инвалидам Отечественной войны [11, л. 26].

Кроме выдачи денежных дотаций, органы власти обязаны были содействовать улучшению материально-бытовых условий инвалидов Отечественной войны. Но не везде эта сторона деятельности городского и районного начальства получила развитие. Как показывают архивные документы, вопросы об оказании помощи инвалидам Отечественной войны редко решались сразу и справедливо [18, л. 136]. Так, инвалидам Коган и Иванушкину (Дзержинский район г. Казани) было выдано 8 ордеров на получение различных промтоваров, а инвалиду Насых (проживающему в том же районе), несмотря на его тяжелое социальное положение - ни одного. Жалоба от инвалида II-ой группы Козловой с просьбой устроить ее в инвалидный дом пролежала в Алькеевском райсобесе без движения 21 день [11, л. 27].

Вместе с тем в архивных источниках встречаются и яркие примеры заботливого отношения администрации к запросам инвалидов. В частности, внимательным подходом к людям, находившимся в его подчинении, отличался директор свиноводческого совхоза «Нырты» Татарской АССР Ахметзянов. Он знал всех работающих инвалидов и оказывал им всемерную поддержку. Например, когда инвалид Терешин демобилизовался из Красной армии, дирекция предоставила ему возможность приобрести по фондовой цене корову (за 180 руб.). Большую помощь получил и инвалид Хисамов. После возвращения с фронта вместо разбитой квартиры он получил добротный дом [6, л. 7].

В городах тоже предпринимались шаги по облегчению положения инвалидов войны. В целях упорядочения снабжения их продовольствием с середины 1943 г. начали открываться специальные магазины и столовые закрытого типа, выдавались ордера на приобретение промышленных товаров [19, л. 109] и т.п. В 1943 г. в ТАССР начал функционировать фонд помощи семьям военнослужащих и инвалидов [20, c. 12-13]. 
Таким образом, изучение документальных материалов показывает, что в годы войны в Татарской АССР реализовывался целый комплекс мер, направленный на поддержку инвалидов Великой Отечественной войны. Государственная помощь этой категории граждан включала в себя денежные выплаты, производственное обучение, перепрофилирование в случае неспособности работать по прежней специальности, содействие в трудоустройстве и решении социально-бытовых проблем и т.п. Многим инвалидам приходилось начинать свою жизнь практически заново, поэтому необходимо было помочь им быстро социально адаптироваться. К сожалению, органы власти, в функции которых входила организация реабилитации и социальной защиты инвалидов, не всегда удовлетворительно справлялись с возложенными на них задачами, о чем свидетельствуют встречающиеся в источниках факты халатно-бюрократического отношения со стороны отдельных чиновников к нуждам инвалидов, случаи расхищения денежных средств, волокиты при решении жизненно важных вопросов.

\section{СПИСОК ЛИТЕРАТУРЫ:}

1. Зинич М.С. Будни военного лихолетья. 19411945. В 2 вып. Вып. 2. М.: РАН, Ин-т рос. истории, 1994. $143 \mathrm{c}$.

2. Синицын А.М. Всенародная помощь фронту: О патриотических движениях советского народа в годы Великой Отечественной войны 1941-1945 гг. 2-е изд. М.: Воениздат, 1985. 319 с.

3. Палецких Н.П. Социальная политика на Урале в период Великой Отечественной войны. Челябинск: Изд-во Челябинского гос. агроинж. ун-та, 1995. $184 \mathrm{c}$.

4. Панарина Е.В. Решение социальных проблем населения Дона и Северного Кавказа в годы Великой
Отечественной войны. 1941-1945 гг. Армавир: РИЦ АГПУ, 2009. $411 \mathrm{c}$.

5. Шалак А.В. Социальные проблемы населения Восточной Сибири (1940-1950-е гг.). Иркутск: Издво Иркут. гос. экон. акад., 2000. 354 с.

6. Национальный архив Республики Татарстан (далее-НАРТ). Ф. Р-128. Оп. 2. Д. 27.

7. НАРТ. Ф. Р-128. Оп. 2. Д. 171.

8. История СССР с древнейших времен до наших дней. Т. 10. М.: Наука, 1973. 782 с.

9. Центральный государственный архив историко-политической документации Республики Татарстан (далее - ЦГА ИПД РТ). Ф. 26. Оп. 13. Д. 15.

10. Писаренко И.С. Советское законодательство о трудоустройстве инвалидов во время Великой Отечественной войны // Актуальные проблемы гуманитарных и естественных наук. М., 2014. № 7-1. С. 7885.

11. ЦГА ИПД РТ. Ф. 15. ОП. 5. Д. 690.

12. НАРТ. Ф. Р-128. Оп. 2. Д. 57.

13. Государственный архив Российской Федерации (далее - ГАРФ). Ф. А-413. Оп. 1. Д. 531.

14. НАРТ. Ф. Р-3610. Оп. 1. Д. 425.

15. ЦГА ИПД РТ. Ф. 48. ОП. 3. Д. 290.

16. ЦГА ИПД РТ. Ф. 48. Оп. 3. Д. 355.

17. ГАРФ. Ф. А-339. Оп. 1. Д. 439.

18. НАРТ. Ф. Р-3610. Оп. 1. Д. 461.

19. НАРТ. Ф. Р-3610. Оп. 5. Д. 62.

20. Татарская АССР в годы Великой Отечественной войны: сб. документов и материалов / сост. Х.Г. Гимади. Казань: Татгосиздат, 1948. 169 с.

Статья подготовлена при поддержке РФФИ и Правительства Республики Татарстан, проект № 17-11-16014 а(р) «Производственные отношения в советское время: содержание и трансформационные процессы. 1920-1980-е г2. (на примере Татарстана)».

\title{
SOCIAL ADAPTATION AND EMPLOYMENT OF DISABLED PEOPLE DURING THE GREAT PATRIOTIC WAR (ON THE MATERIALS OF THE TATAR ASSR)
}

(C) 2017

\author{
Kabirova Aislu Sharipzyanovna, doctor of historical sciences, \\ leading researcher of Contemporary History Department \\ Institute of History named after Sh. Mardzhani of Tatarstan Republic Academy of Sciences \\ (Kazan, Russian Federation)
}

\begin{abstract}
The article deals with the problems of social adaptation of disabled veterans of the Great Patriotic War in the Tatar Autonomous Soviet Socialist Republic after their return to peaceful life. Based on the documentary materials extracted from the funds of the federal and Tatarstan archives The author characterizes forms of state support for war-maimed people, resolution of their production training and employment, appointment of pensions, opening of boarding houses, organization of health care services, etc. It is noted that for the majority of disabled people this targeted support was often a determining factor in ensuring their livelihoods. The employment of disabled veterans of the Patriotic War made it possible to solve a two-fold problem: in the conditions of an acute shortage of workers, a new personnel reserve was created for the economy and at the same time social protection of veterans returned after treatment in hospitals was provided. Many disabled veterans of the Great Patriotic War showed themselves well in the workplace, became leaders and were nominated for leadership positions. But there were those who led an immoral lifestyle, begging. The authorities, called to solve the issues of social rehabilitation of disabled people, did not always cope with the tasks assigned to them. Evidence of this is the facts of the soullessly-bureaucratic attitude of certain officials to the needs and requests of disabled people, cases of appropriation of funds and squandering of state
\end{abstract} funds.

Keywords: Great Patriotic War; Tatar ASSR; front-line soldiers; war invalids; targeted support; state aid; social adaptation; social protection; rehabilitation; pensions; benefits; Labor policy; industrial training; employment; boarding schools for disabled people. 